\title{
COMPARISON OF JAPANESE AND CHINESE CLOTHING EVALUATIONS BY EXPERTS TAKING INTO ACCOUNT MARKETABILITY
}

\author{
KyoungOk Kim ${ }^{1}$, Masayuki Takatera ${ }^{1}$, Chunhong Zhu $^{2}$, and Tsuyoshi Otani ${ }^{3}$ \\ 'Division of Kansei and Fashion Engineering, Institute for Fiber Engineering (IFES), \\ Interdisciplinary Cluster for Cutting Edge Research (ICCER), Shinshu University, Ueda, Nagano, Japan \\ ${ }^{2}$ Interdisciplinary Graduate School of Science and Technology, Shinshu University, Japan \\ ${ }^{3}$ Faculty of Textile Science and Technology, Shinshu University, Japan \\ Corresponding author e-mail: takatera@shinshu-u.ac.jp
}

\begin{abstract}
:
To better understand the reasons for the marketability of clothing now designed and sold in China and Japan, we asked Japanese and Chinese experts to evaluate Chinese and Japanese brands of clothing currently for sale in the Japanese market. The marketability of the Chinese apparel items in the Japanese market was evaluated by the Japanese experts. Five Japanese jackets were purchased from a department store in Tokyo, and ten items of Chinese clothing were purchased from a department store in Beijing. Five of the Chinese clothing samples were judged as impossible to sell in Japanese department stores primarily because the sewing quality was incompatible with Japanese requirements, the designs were outdated, and the materials were of low quality. However, the other five Chinese clothing samples received high evaluations of marketability in Japan. We found that Japanese experts focused on general design and sewing finish, while Chinese experts considered more general design points. Thus, our results indicate that clothing is evaluated differently in Japan and China. We conclude that it is necessary to consider the respective evaluation points used in each country as we pursue globalisation.
\end{abstract}

\section{Keywords:}

Chinese Apparel; Japanese Apparel; Clothing Evaluation; Apparel Expert

\section{Introduction}

The scale of the Chinese clothing market is currently greater than 12 trillion yen, which is second to that of the USA; China thus competes with Japan for second place. The growth rate of the clothing market in China is high [1]. The Chinese apparel industry has gradually acquired high-quality manufacturing ability at low costs. Based on this ability, Chinese companies are now trying to enter global markets, including that of Japan and Europe [11, 12].

While the Japanese apparel market remains relatively large scale, it has recently been experiencing saturation and reductions in size. Many global companies with products in both the low and high price ranges have been entering the Japanese market. Although Japanese fashion products designed by Japanese companies are generally superior in the domestic market, their international presence is considerably smaller. With a few exceptions, most of such Japanese fashion products sell poorly in overseas markets. Especially, in the Chinese market, some European and American luxury brands and a few Korean apparel brands have become famous and have shown high sales in China. More European apparel makers are trying to enter the Chinese market [12].

Recently, at least $80 \%$ of the clothing sold in Japan is manufactured in China [2]. According to trade statistics, the value of imports of clothing and accessories in 2010 was 2753 billion yen. Of these, imports from China comprised $76.4 \%$, for a value of 2.1 trillion yen [1, 2]. It is assumed that most of the clothing products, imported from China and sold in Japan, are produced under the production control of Japanese companies. The clothing is of satisfactory quality to sell in Japan. The situation is similar in European market as well.

Globally speaking, current Japanese quality management standards are said to be too severe and excessively strict [3]. In addition, some industry observers believe that Japanese clothing does not sell well in the Chinese market owing to differences in design and size [4]. This means that the market situation and manufacturing condition of fashion market in each country are different. To better understand the state of the global fashion market, therefore, it is necessary to know the current state of Chinese apparel in the global market.

There are some studies on the consumer behaviour and marketing in China [5, 8]. The Chinese preferences of brands and body images were also investigated $[6,7]$. The effects of consumers' appearance and body on their behaviour for shopping were investigated [9, 10]. However, those studies were not considered the characteristic of clothing itself. Popular clothing in China may not be popular in Japan and vice versa.

To understand the difference of the marketable clothing, we investigated the characteristics of clothes designed and sold in China and Japan. The marketability considered, the clothing characteristic will be one important factor that may show the customers' preference. Thus, we also investigate the marketability of Chinese apparel in Japanese department stores for Chinese and Japanese apparel makers. By investigating 
the marketability of clothing, we can understand the customers' preference.

The sample clothes were evaluated by clothing experts who have a career in apparel industry or education in both Japan and China. We assumed that they understand the customers' preference and marketability of each country. The experts described the points of evaluation on which the clothing experts from each country focus. If their focused points were different, it will show the difference of the preference of customers in each country. Thus, we compared these points of focus of both countries and clarified the differences. Understanding customer preferences will help designers and manufacturers to make clothing which satisfy customers in each country.

\section{Experimental}

To understand the differences in clothing evaluation focus points between Japan and China, the characteristics of clothes designed and sold in Japan was investigated. The marketability of the Chinese apparel items in the Japanese market was evaluated by the Japanese experts. We refer to Chinese brand clothing sold in China as Chinese apparel, and Japanese brand clothing sold in Japan as Japanese apparel.

A jacket is broadly sold in Japan and Chain and high sewing skills are necessary to make it. Jacket can be a representative of the apparel industry. Thus we selected jacket as an experimental item. Five Japanese jackets were purchased for evaluation from a department store in Tokyo, and ten items of Chinese clothing (two dresses, eight jackets) were purchased for evaluation from a department store in Beijing. The brands were suggested by apparel experts. Among the brands, one brand did not make jackets. Thus, two dresses were selected instead of jackets. The specifications of the samples are shown in Table 1. To sell garments, business experts evaluate the garments based on their experiences. Professors educate the evaluation of garments. Thus we chose experts including a professor, a designer, a pattern maker, an art director and a merchandiser as evaluators. Seven Japanese apparel experts (two university professors, two designers, a pattern maker, and two merchandisers) and ten Chinese apparel experts (eight university professors, an art director, and a designer) evaluated the samples. Details about the evaluators are shown in Table 2. As an experimental condition, it was hard to employ the experts as a subject. Thus the members of experts group were different in Japan and China. The experts were not informed of the item specifications, including their purchase price, brand, materials, and country of manufacture. They examined the samples by observing them being worn and/or putting them on a dressmaker's dummy and by touching them.

The sample items were evaluated on the basis of their 1) materials, 2) colours, 3) silhouette (shape and outline), 4) design emphasis points (distinct characteristic or feature in the garments such as details, colour and textile, etc.), 5) designer ability, 6) pattern maker ability, and 7) sewing finish. The marketability of the items in Japanese department stores was judged by the experts (possible or impossible). The experts were also instructed to suggest an estimate of the retail prices of the items.

Each point of evaluation was scored on a $0-2$ or $0-3$-point scale. Evaluators were required to provide the reason for each score they gave. Points were accumulated to give an average score out of a total score of 100 . The evaluation point scoring was performed by principal component analysis (PCA) to investigate the structure of the evaluations. Evaluators were required to provide the reason for each score they gave. The reasons for each evaluation provided by the experts were summarised.

\section{Comparison of clothing evaluation results}

\subsection{Clothing evaluation results between both countries}

The average scores (out of 100) of the samples as scored by the Japanese and Chinese experts are shown in Figure 1. The average of all scores for all samples was 47.5 by the Japanese experts and 70.1 by the Chinese experts, indicating that the Japanese experts were stricter in their evaluations than the Chinese.. The score rankings are shown in Table 3. The rankings of the samples were also different depending on the country.

The Japanese experts gave higher scores to samples J9, C14 and $\mathrm{J} 15$, all with scores over 60 . To samples $\mathrm{C} 4, \mathrm{C} 11, \mathrm{C} 12$, and C13, the Japanese experts gave lower scores, all under 40. The Chinese experts, on the other hand, evaluated samples C5, J7, C8, J9, C14 and J15, all with scores over 70. Sample C10 was given the lowest score (under 50 ) by the Chinese experts. Samples J9, C14, and J15 were highly evaluated by the experts of both countries.

These results indicate that there are common points of evaluation with respect to generally highly evaluated clothing in both countries. However, while samples C4, C11, C12, and C13 were poorly evaluated by the Japanese experts, they were given mid-range scores by the Chinese experts. In contrast, samples $\mathrm{C} 2, \mathrm{~J} 3$, and $\mathrm{J} 6$ were highly evaluated by the Japanese experts but given comparatively lower scores by the Chinese experts. These results indicate that there are some different evaluation points between the two countries.

\subsection{Results of principal component analysis}

We performed a PCA to summarise the evaluation structure of each evaluator group. The principal component loading results are shown in Figures 2 and 3.

The PCA results showed that the principal component loadings of the first principal component by the Japanese experts were as follows: silhouette 0.94 , materials 0.89 , designer ability 0.87 , pattern maker ability 0.85 , colours 0.82 and sewing finish 0.80 . The contribution ratio of the first principal component was $63.8 \%$. In the second principal component of the Japanese experts, the principal component loadings of design emphasis points showed a large value, -0.96 . The contribution ratio of 
Table 1. Sample specifications

\begin{tabular}{|c|c|c|c|c|c|c|c|}
\hline $\begin{array}{c}\text { Sample } \\
\text { name }\end{array}$ & $\begin{array}{l}\text { Sample } \\
\text { picture }\end{array}$ & $\begin{array}{l}\text { Brand } \\
\text { country }\end{array}$ & $\begin{array}{l}\text { Retail } \\
\text { price }\end{array}$ & $\begin{array}{c}\text { Sample } \\
\text { name }\end{array}$ & $\begin{array}{l}\text { Sample } \\
\text { picture }\end{array}$ & $\begin{array}{l}\text { Brand } \\
\text { country }\end{array}$ & Retail price \\
\hline C1 & & China & $\begin{array}{l}\text { CNY } 850 \\
\quad(J P Y \\
13,600)\end{array}$ & J9 & & Japan & $\begin{array}{c}\text { CNY } 4528 \\
(J P Y ~ 72,450)\end{array}$ \\
\hline $\mathrm{C} 2$ & & China & $\begin{array}{l}\text { CNY } 795 \\
\quad(J P Y \\
12,720)\end{array}$ & C10 & & China & $\begin{array}{c}\text { CNY } 3128 \\
(J P Y 50,048)\end{array}$ \\
\hline $\mathrm{J} 3$ & & Japan & $\begin{array}{l}\text { CNY } 1575 \\
\quad(J P Y \\
25,200)\end{array}$ & C11 & & China & $\begin{array}{c}\text { CNY } 1149 \\
\text { (JPY 18,384) }\end{array}$ \\
\hline C4 & & China & $\begin{array}{c}\text { CNY } 589 \\
\text { (JPY 9424) }\end{array}$ & C12 & & China & $\begin{array}{c}\text { CNY } 799 \\
\text { (JPY 12,784) }\end{array}$ \\
\hline C5 & & China & $\begin{array}{l}\text { CNY } 1068 \\
\quad(J P Y \\
17,088)\end{array}$ & C13 & & China & $\begin{array}{c}\text { CNY } 2598 \\
(\text { JPY 41,568) }\end{array}$ \\
\hline J6 & & Japan & $\begin{array}{l}\text { CNY } 1575 \\
\quad(J P Y \\
25,200)\end{array}$ & C14 & & China & $\begin{array}{c}\text { CNY } 2897 \\
\text { (JPY 46,352) }\end{array}$ \\
\hline $\mathrm{J} 7$ & & Japan & $\begin{array}{l}\text { CNY } 1838 \\
\quad(J P Y \\
29,400)\end{array}$ & $\mathrm{J} 15$ & & Japan & $\begin{array}{c}\text { CNY 1811 } \\
\text { (JPY 28,980) }\end{array}$ \\
\hline C8 & & China & $\begin{array}{l}\text { CNY } 2592 \\
\quad(J P Y \\
41,472)\end{array}$ & \multicolumn{4}{|c|}{$\begin{array}{l}\text { *Note: 'J' refers to Japanese brand; 'C' refers to Chinese } \\
\text { brand. } \\
\text { *Retail price was converted at a rate of } 1 \mathrm{CNY}=16 \mathrm{JPY} \text {. }\end{array}$} \\
\hline
\end{tabular}


Table 2. Evaluators' details in Japan and China

\begin{tabular}{|c|c|c|c|c|c|}
\hline \multicolumn{2}{|c|}{ Japan } & \multicolumn{2}{c|}{ China } \\
\hline No. & Gender & Occupation & No. & Gender & Occupation \\
\hline JE1 & Female & University professor & CE1 & Female & University professor \\
\hline JE2 & Male & University professor/designer & CE2 & Male & University professor \\
\hline JE3 & Female & University professor & CE3 & Female & University professor \\
\hline JE4 & Female & University professor/designer & CE4 & Female & University professor \\
\hline JE5 & Female & Pattern maker & CE5 & Female & University professor \\
\hline JE6 & Female & Merchandiser & CE6 & Female & University professor/designer \\
\hline JE7 & Male & Merchandiser & CE7 & Male & University professor \\
\hline & & & CE8 & Male & University professor/art producer \\
\cline { 3 - 6 } & & & CE9 & Male & University professor \\
\cline { 3 - 5 } & & CE10 & Male & University professor \\
\cline { 3 - 5 }
\end{tabular}

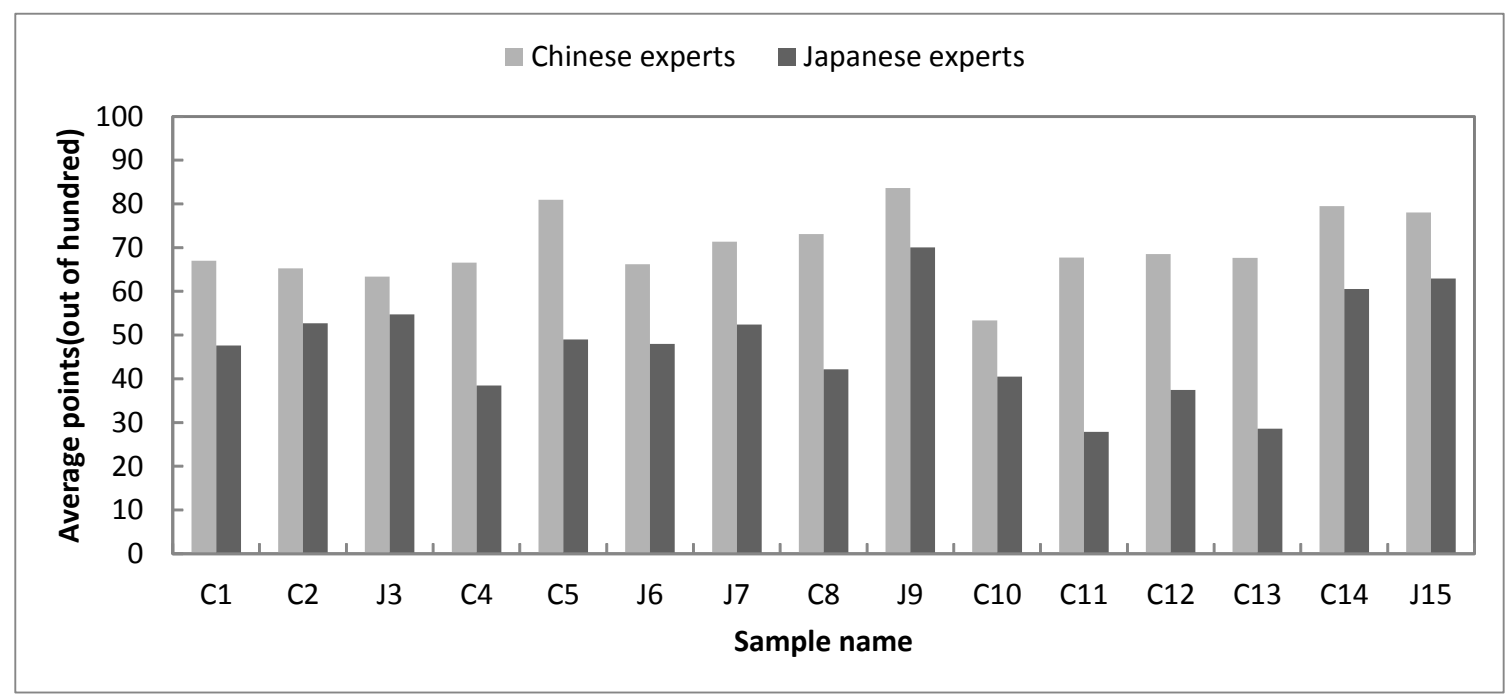

Figure 1. Average evaluation scores of samples (out of 100)

Table 3. Sample rankings according to the obtained scores

\begin{tabular}{|c|c|c|c|c|c|}
\hline \multirow{2}{*}{ Sample } & \multicolumn{2}{|c|}{ Rank } & \multirow{2}{*}{ Sample } & \multicolumn{2}{|c|}{ Rank } \\
\hline & Chinese & Japanese & & Chinese & Japanese \\
\hline $\mathrm{C} 1$ & 10 & 9 & $\mathrm{C} 8$ & 5 & 10 \\
\hline $\mathrm{C} 2$ & 13 & 5 & J9 & 1 & 1 \\
\hline J3 & 14 & 4 & C10 & 15 & 11 \\
\hline $\mathrm{C} 4$ & 11 & 12 & C11 & 8 & 15 \\
\hline C5 & 2 & 7 & $\mathrm{C} 12$ & 7 & 13 \\
\hline J6 & 12 & 8 & $\mathrm{C} 13$ & 9 & 14 \\
\hline J7 & 6 & 6 & C14 & 3 & 3 \\
\hline & & & J15 & 4 & 2 \\
\hline
\end{tabular}




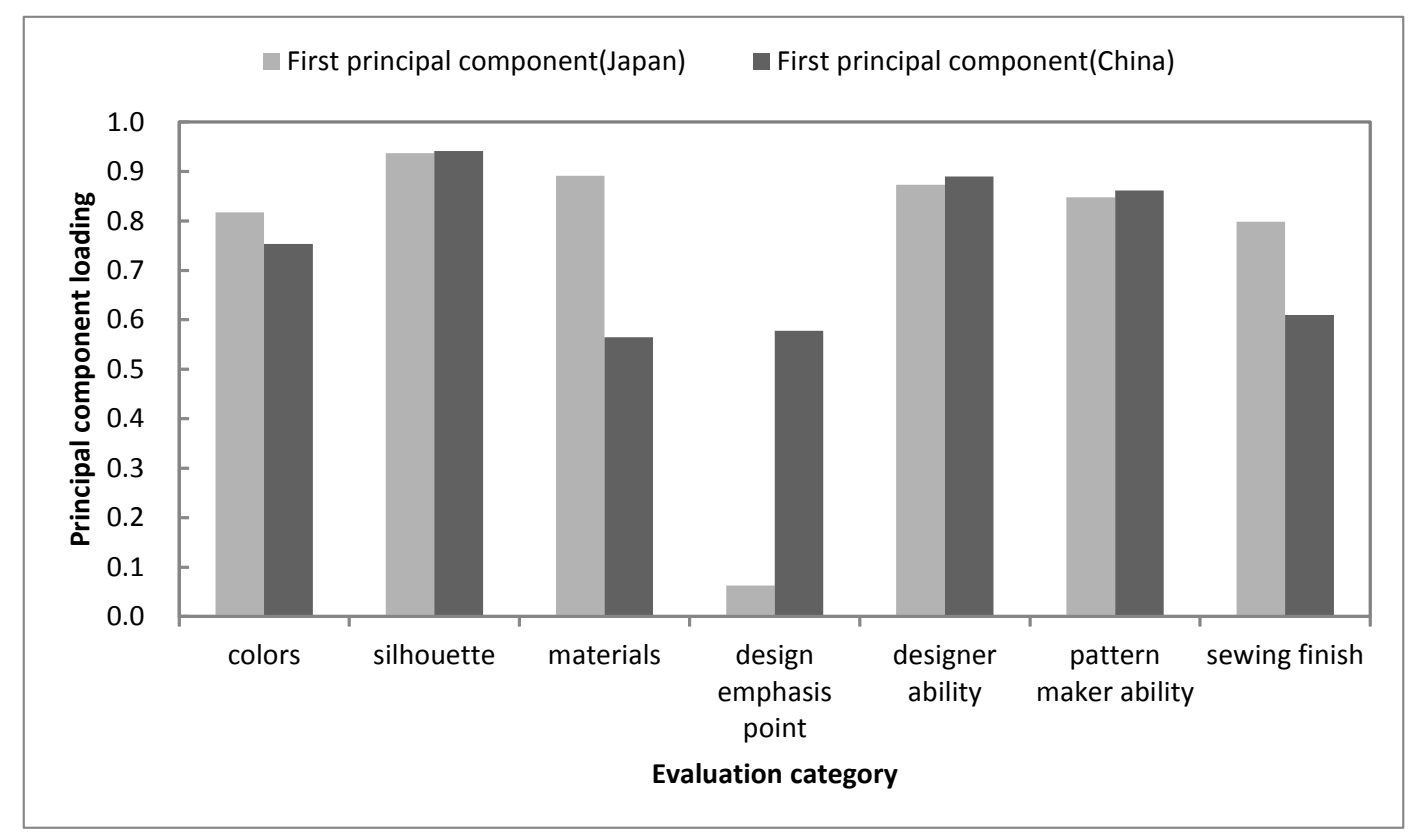

Figure 2. Comparison of principal component loading results of the first principal components by the Japanese and Chinese experts

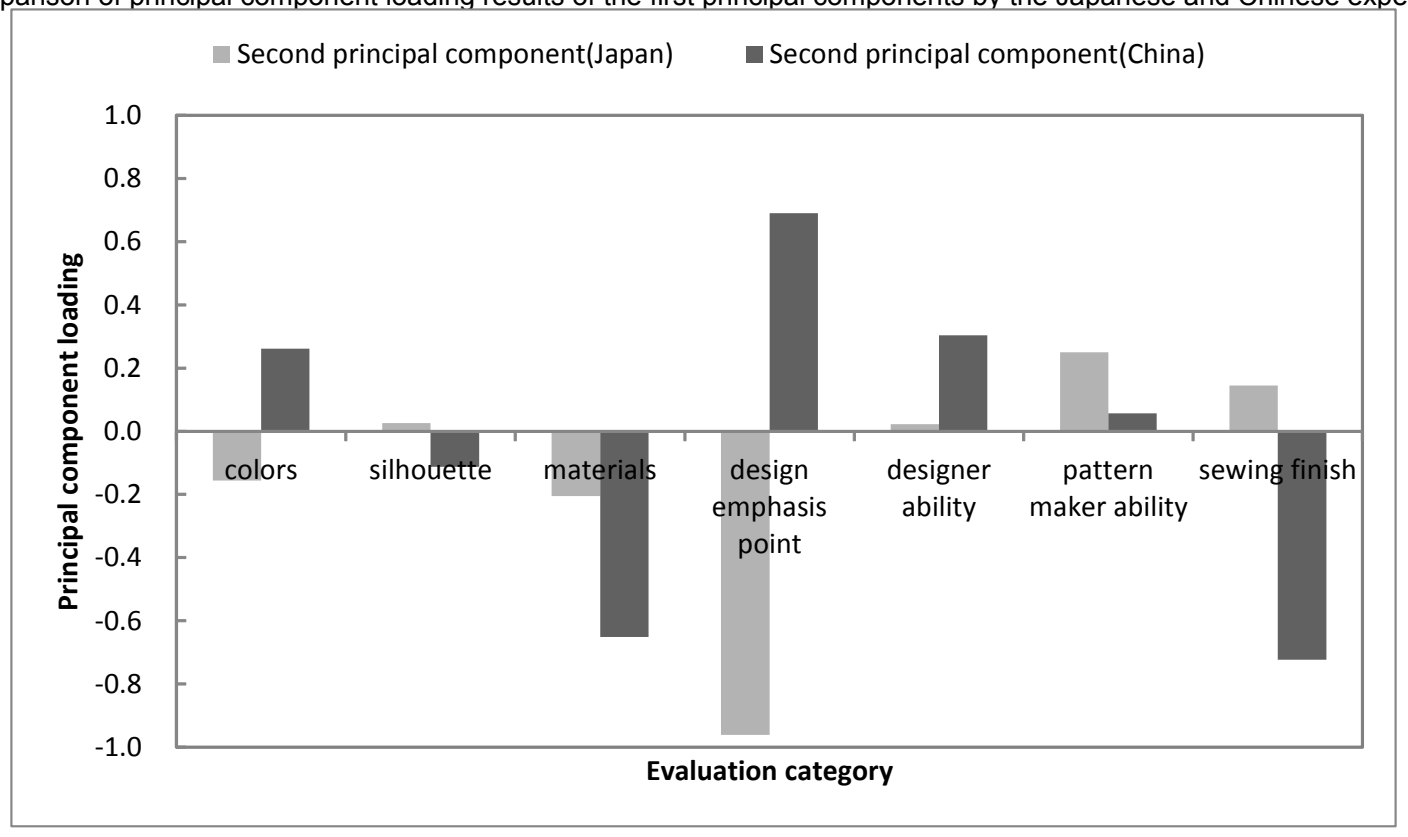

Figure 3. Comparison of principal component loading results of the second principal components by the Japanese and Chinese experts

this second principal component was $15.4 \%$. Therefore, the correlation of each evaluation item was high by Japanese experts, indicating that they evaluated the samples while taking into consideration each sample's general design qualities in a comprehensive manner.

The principal component loading results of the first principal component by the Chinese experts were as follows: silhouette 0.94 , designer ability 0.89 , and pattern maker ability 0.86 . The contribution ratio of the first principal component was $57.3 \%$. These results indicate that the Chinese experts took the factors of silhouette, designer's ability, and pattern maker's ability more into consideration compared with the Japanese experts. As for the results of the principal component loading of the second principal component by the Chinese experts, the characteristics of materials, sewing finish, and design emphasis points showed higher values than the others. The contribution ratio of this second principal component was $22.9 \%$.

Figures 2 and 3 show a comparison of the principal component loading results of the first and second principal components, respectively, by the Japanese and Chinese experts. Comparing both sets of results, we can conclude that the Chinese experts took design emphasis points into consideration more than the Japanese experts did, as shown in Figure 2. The Japanese experts, on the other hand, took the factors of materials and sewing finish into consideration more than the Chinese experts did, as shown in Figure 3.

The relationship between the first and the second principal component loadings between Japanese and Chinese experts is shown in Figure 4. The Japanese experts evaluated design 
emphasis points independently from the other evaluation items, while the Chinese experts evaluated materials and sewing finish independently from the other evaluation items. These results also show that the evaluation points are different depending on the country.

In conclusion, we found that the Japanese experts focused on overall design and sewing finish, while the Chinese experts tended to focus more on design emphasis points. The materials and sewing finish of the samples were evaluated by the Chinese experts independently from the overall design points. Thus, we can conclude that clothing is evaluated differently in Japan and China. We further conclude that it is necessary to examine the primary evaluation points considered to be most important in each country as we pursue globalisation.

\section{Marketability of Chinese apparel in Japanese}

\section{department stores by Japanese evaluators}

\subsection{Results of marketability for Chinese apparel}

The marketability of the Chinese apparel items in the Japanese market was evaluated by the abovementioned Japanese experts. The marketability score was obtained by adding the scores given by the experts who evaluated the clothing as saleable. Table 4 shows the marketability scores. All of the Japanese apparel items were evaluated as having high marketability. However, among the Chinese apparel items, only half of the samples $(C 1, C 2, C 5, C 12$, and $C 14)$ were evaluated as having high marketability. The other samples $(\mathrm{C} 4, \mathrm{C} 8, \mathrm{C} 10$, $\mathrm{C} 11$, and $\mathrm{C} 13$ ) were judged as being impossible to sell in Japanese department stores.

The category scores for the samples with lower expert scores for marketability in Japan are shown in Table 5. While those samples showed high scores in the 'design emphasis' category, the experts also commented that there are too many design elements in the items and also that the entire design was out of fashion. The samples that showed high evaluation scores are also shown in Table 6. The characteristic of these samples included having a good silhouette, good materials, good colours, and/or good patterns. These samples also had good points of design emphasis and comparatively high sewing finish quality. The main reasons given by the experts for the items being unsaleable were that the required sewing quality was insufficient to meet Japanese requirements, the designs were outdated (even those samples currently being sold), and the materials were evaluated as being of low quality. However, the Chinese clothing samples C1, C2, C5, C12, and $\mathrm{C} 14$, which received high evaluation scores of marketability in Japan, were evaluated highly in the categories of design and sewing quality. Therefore, to obtain a generally higher evaluation, Chinese apparel needs to improve in the aspects of sewing finish, quality of materials, and design to be more saleable in the Japanese apparel market.

The correlation coefficients between the experts' saleable evaluations and the averages of the obtained general scores for the evaluation categories are shown in Figure 5. With the exception of 'design emphasis points', all the categories showed high correlation coefficients. This low correlation coefficient value for the design emphasis points category indicates that design was emphasised in the Chinese apparel items. However, the entire evaluation was still low compared with the Japanese apparel, in particular with respect to the category of sewing finish.

To obtain a high correlation of regression equation than single correlation, a multiple regression analysis was performed assuming the experts' saleable evaluations as a response variable and the evaluation items as explanatory variables. As a result, the adjusted multiple correlation coefficient was 0.72 , which was lower than some single correlation coefficient. Thus, it was not possible to make a predictive equation using multiple regressions.

The results indicate that even for those samples evaluated as having design emphasis points, their marketability in Japan could be improved through greater cooperation between designers, pattern makers, and sewing factories, and additionally, through improved sewing skills.

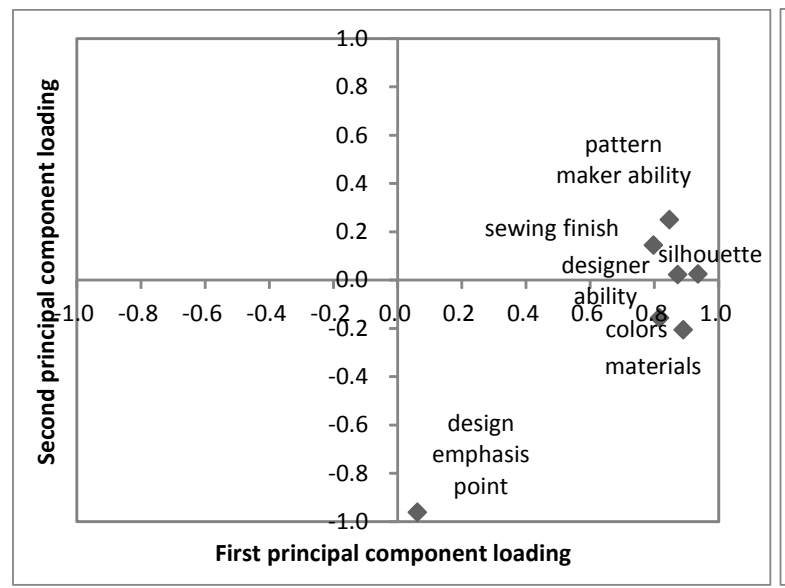

(a) Japanese

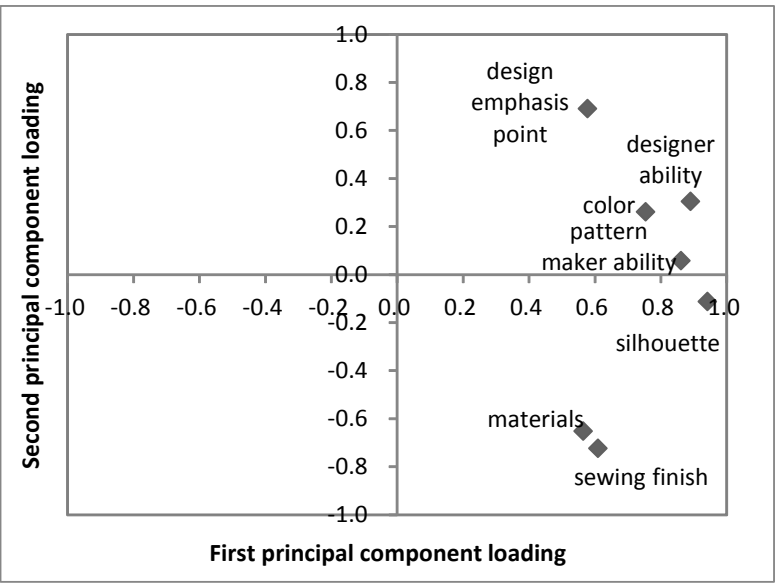

(b) Chinese

Figure 4. Relationship between the first and second principal component loadings for Japanese and Chinese experts 
Table 4. Experts' evaluation scores regarding the marketability of Chinese apparel $(\mathrm{N}=7)$

\begin{tabular}{|c|c|c|c|c|c|c|c|c|c|c|c|c|c|c|c|}
\hline Sample number & $\mathbf{C 1}$ & $\mathbf{C 2}$ & $\mathbf{J 3}$ & $\mathbf{C 4}$ & $\mathbf{C 5}$ & $\mathbf{J 6}$ & $\mathbf{J 7}$ & $\mathbf{C 8}$ & $\mathbf{J 9}$ & $\mathbf{C 1 0}$ & $\mathbf{C 1 1}$ & $\mathbf{C 1 2}$ & $\mathbf{C 1 3}$ & $\mathbf{C 1 4}$ & $\mathbf{J 1 5}$ \\
\hline $\begin{array}{c}\text { Experts' scores: } \\
\text { saleable }\end{array}$ & 5 & 5 & 7 & 2 & 4 & 7 & 6 & 2 & 7 & 3 & 1 & 4 & 1 & 5 & 6 \\
\hline $\begin{array}{c}\text { Experts' scores: } \\
\text { unsaleable }\end{array}$ & 2 & 2 & 0 & 5 & 3 & 0 & 1 & 5 & 0 & 4 & 6 & 3 & 6 & 2 & 1 \\
\hline
\end{tabular}

Table 5. Evaluation scores of samples with lower scores for marketability in Japan ( $N=7)$

\begin{tabular}{|c|c|c|c|c|c|c|c|c|}
\hline $\begin{array}{c}\text { Sample } \\
\text { number }\end{array}$ & $\begin{array}{c}\text { Experts' } \\
\text { marketability } \\
\text { score }\end{array}$ & Silhouette & Materials & Colours & $\begin{array}{c}\text { Sewing } \\
\text { finish }\end{array}$ & $\begin{array}{c}\text { Design } \\
\text { emphasis } \\
\text { points }\end{array}$ & $\begin{array}{c}\text { Designer's } \\
\text { ability }\end{array}$ & $\begin{array}{c}\text { Pattern } \\
\text { maker's } \\
\text { ability }\end{array}$ \\
\hline C4 & 2.0 & 3.3 & 1.4 & 2.9 & 5.7 & 9.3 & 1.4 & 2.9 \\
\hline C8 & 2.0 & 2.4 & 2.4 & 3.3 & 5.0 & 10.0 & 2.9 & 3.6 \\
\hline C10 & 3.0 & 2.9 & 3.3 & 1.4 & 5.0 & 8.6 & 2.9 & 4.3 \\
\hline C11 & 1.0 & 1.9 & 2.9 & 3.3 & 0.0 & 7.1 & 2.9 & 1.4 \\
\hline C13 & 1.0 & 1.4 & 1.4 & 2.9 & 3.6 & 5.7 & 2.1 & \\
\hline
\end{tabular}

Table 6. Evaluation scores of samples with higher scores for marketability in Japan $(\mathrm{N}=7)$

\begin{tabular}{|c|c|c|c|c|c|c|c|c|}
\hline $\begin{array}{c}\text { Sample } \\
\text { number }\end{array}$ & $\begin{array}{c}\text { Experts' } \\
\text { marketability } \\
\text { score }\end{array}$ & Silhouette & Materials & Colours & $\begin{array}{c}\text { Sewing } \\
\text { finish }\end{array}$ & $\begin{array}{c}\text { Design } \\
\text { emphasis } \\
\text { points }\end{array}$ & $\begin{array}{c}\text { Designer's } \\
\text { ability }\end{array}$ & $\begin{array}{c}\text { Pattern } \\
\text { maker's } \\
\text { ability }\end{array}$ \\
\hline C1 & 5.0 & 3.3 & 3.8 & 3.3 & 5.0 & 7.9 & 5.0 & 5.0 \\
\hline C2 & 5.0 & 3.8 & 5.7 & 5.2 & 5.7 & 7.9 & 4.3 & 4.3 \\
\hline C5 & 4.0 & 3.3 & 4.8 & 4.8 & 4.3 & 8.6 & 3.6 & 5.0 \\
\hline C12 & 4.0 & 3.3 & 3.8 & 3.3 & 2.1 & 5.7 & 2.9 & 5.0 \\
\hline C14 & 5.0 & 5.2 & 5.2 & 4.8 & 8.6 & 6.4 & 5.0 & 7.1 \\
\hline
\end{tabular}

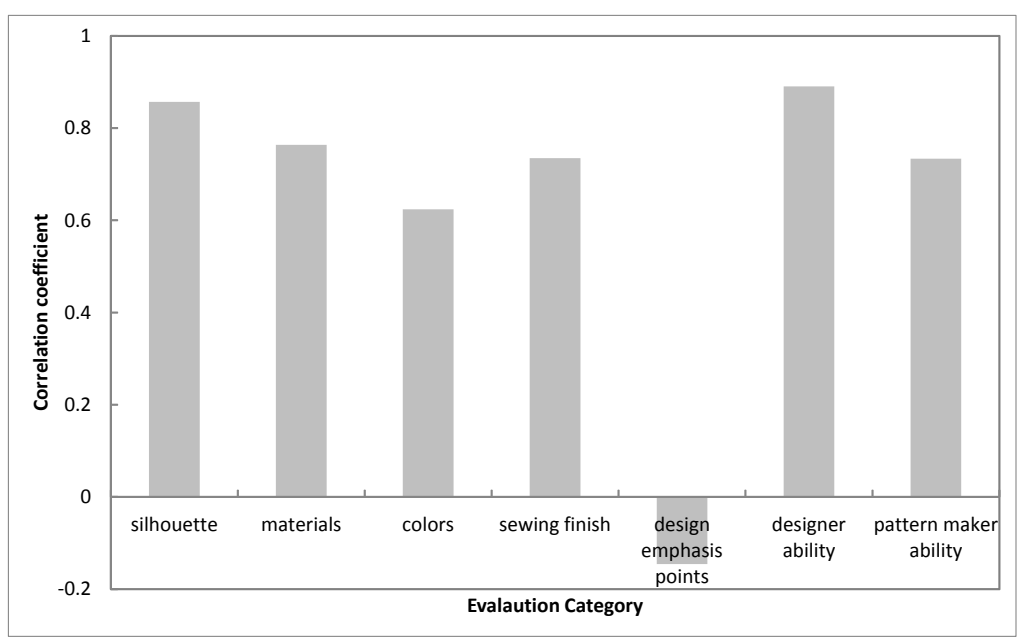

Figure 5. Correlation coefficients between experts' marketability scores and the averages of the obtained general scores of the evaluation categories

\subsection{Evaluated prices of clothing}

The retail prices and the experts' estimated prices of the samples are shown in Figure 6. The price of items judged as unsaleable in Japanese department stores was set as zero JPY. With the exception of the scores of one expert (E1), no correlation was found between the actual purchase and the estimated prices. The estimated prices of the Japanese apparel samples were close to the actual purchase prices. As for the Chinese apparel samples, however, the prices of samples $\mathrm{C} 8, \mathrm{C} 10$, and $\mathrm{C} 13$ were estimated to be less than half of their actual purchase prices (sample C14 was the exception). Even the Chinese clothing samples with an actual retail price of over 40,000 JPY were not estimated by the experts to have such 


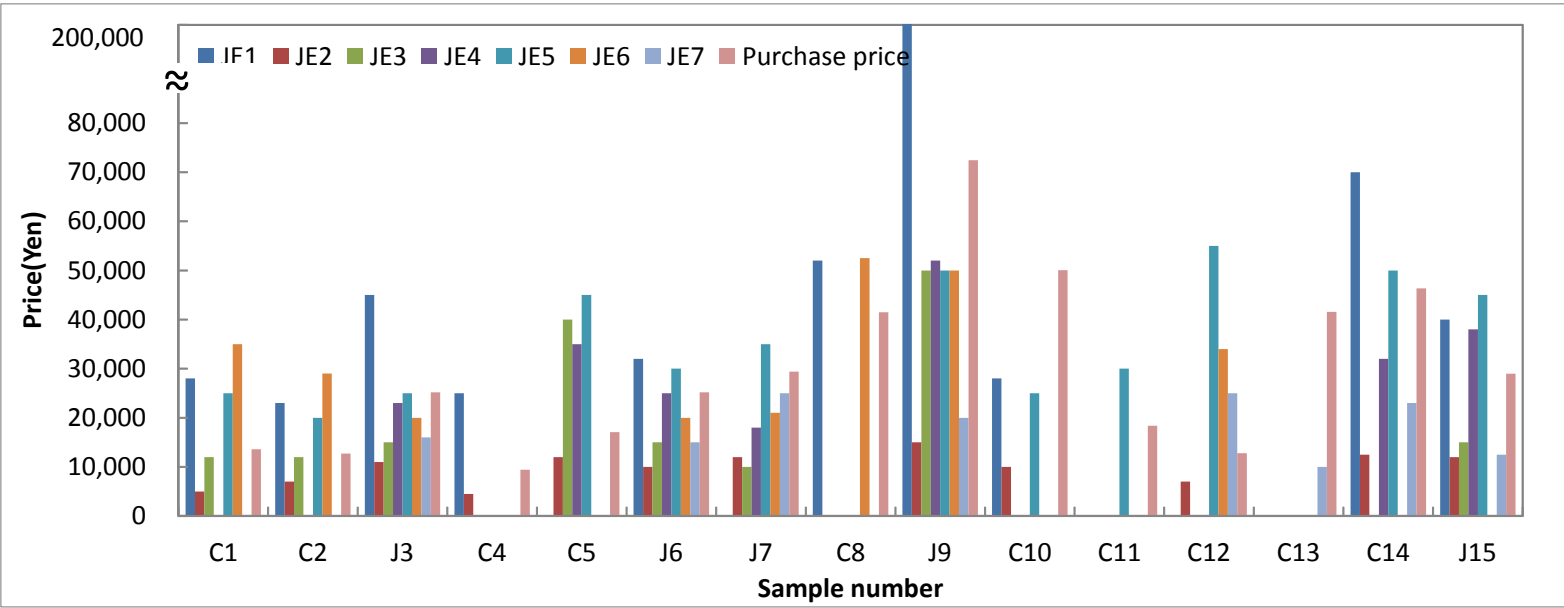

Figure 6. Estimated and actual retail purchase prices of samples by Japanese evaluators

prices in Japan. These results therefore indicate that purchase prices may be decided more by the brand than the actual item characteristics.

\subsection{Evaluated points}

The Japanese evaluators had various career backgrounds, which likely had an influence on their evaluations. Nonetheless, some common points for consideration were identified from their comments regarding the evaluated items. Specifically, they noted that to successfully sell clothing in Japanese department stores, apparel producers should focus on improving seam finishing, pressing marks, and other details such as buttons.

\subsubsection{Design emphasis points and design balance}

Samples with more than three design emphasis points were given low evaluations by the experts. Figure 7 shows those samples that were judged as having too many emphasis design
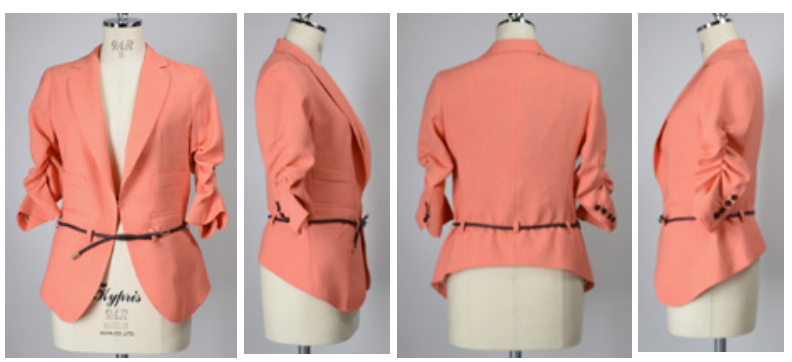

(a) $\mathrm{C5}$ points; C5 was evaluated as having design emphasis points on its pocket, belt, sleeve shirring, and front hem curve; C8 was also found to have design emphasis points on its tuck, patch pocket, and length difference between the front and back. In Japan, apparel with too many design emphasis points is less preferred.

Design balance was also considered to be an important evaluation point in this study. Samples of unbalanced design are shown in Figure 8; samples C4 and C10 were evaluated as having an entirely unbalanced design, while samples $\mathrm{C} 11$ and C13 were evaluated as having sleeve lengths that are too long for the average Japanese body shape.

\subsubsection{Seam finishing}

Most of the experts looked for very high quality in the category of seam finishing. Figures 9 and 10 show examples of clothing with poor and good quality seam finishing, respectively.
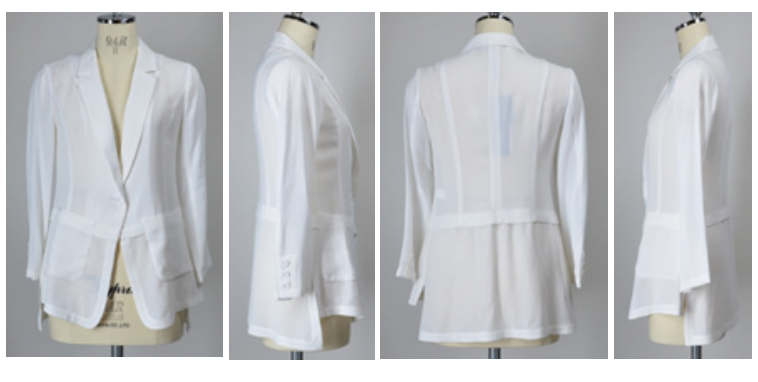

(b) $\mathrm{C} 8$

Figure 7. Examples of excessive design emphasis points

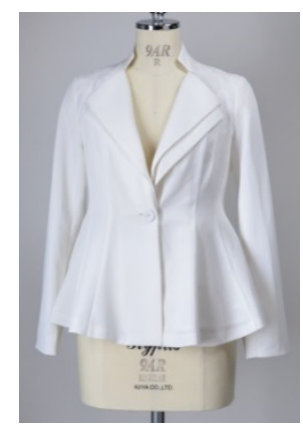

(a) $\mathrm{C} 4$

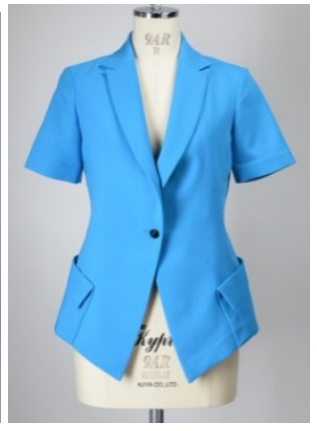

(b) C10

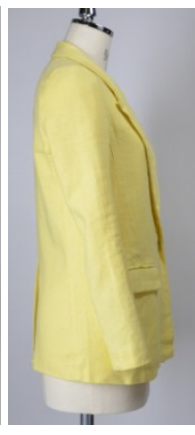

(c) C11

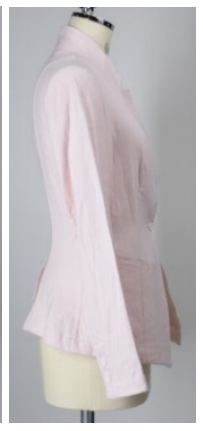

(d) $\mathrm{C} 13$

Figure 8. Examples of unbalanced design 
Interlock seam finishing was especially evaluated as being of poor quality, while piping seam finishing was considered to be of high quality. However, the suitability of textile properties for seam finishing was also considered. Thus, samples with piping seam finishing for thick fabric was evaluated as poor, as shown in Figure 11.

\subsubsection{Pressing mark}

The pressing mark of each sample was also examined. Most of the experts mentioned the pressing mark around the collar and lapel areas in their comments. Figure 12 shows some examples of the pressing marks of the samples.

\subsubsection{Button}

Buttons were another category of quality evaluated by the experts. Figure 13 shows examples that were judged as easy to unbutton. This evaluation was also related to the type of seam finish. The material of the buttons was also evaluated from the aspect of poor or high quality (see Figure 14).

\section{CONCLUSIONS}

To investigate and compare the evaluation points considered to be more important by both Japanese and Chinese apparel

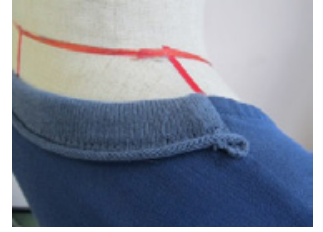

(a) $\mathrm{C} 2$

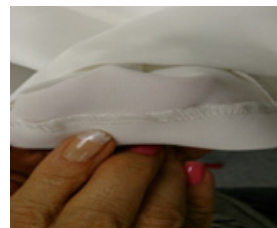

(b) $\mathrm{C} 4$

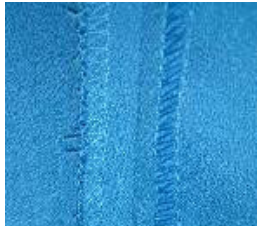

(c) $\mathrm{C} 10$

Figure 9. Poor-quality examples of seam finishing

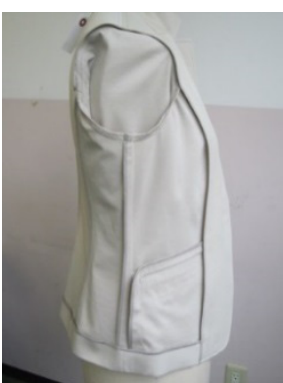

(a) J3

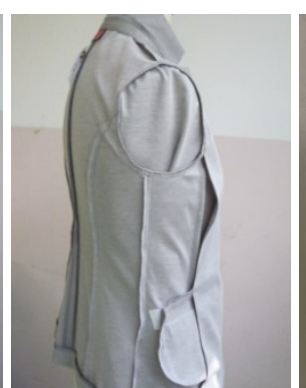

(b) $\mathrm{J} 6$

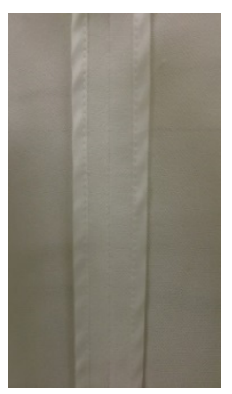

(c) $\mathrm{C} 8$

Figure 10. High-quality examples of seam finishing

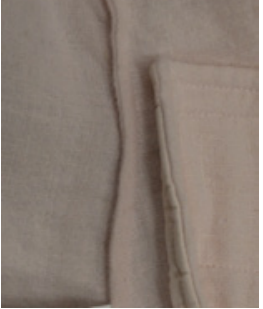

Figure 11. Example of low-quality piping seam finishing (C13)

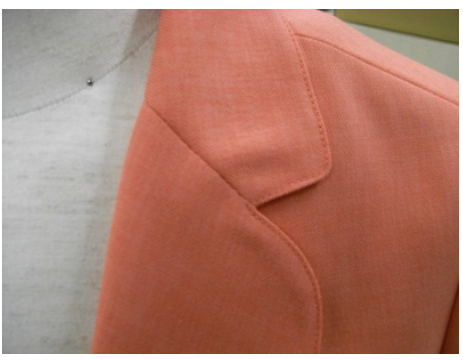

(a) $\mathrm{C5}$

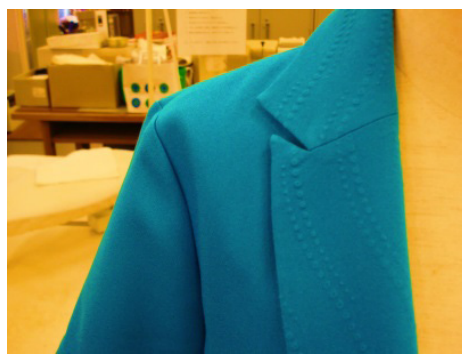

(b) C10

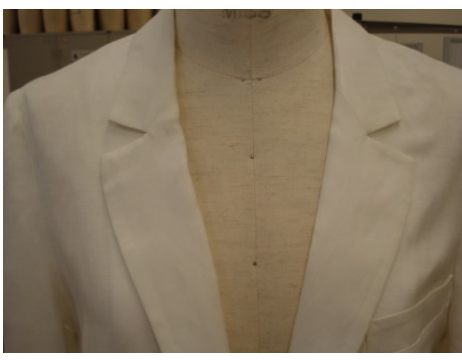

(c) $\mathrm{C} 12$

Figure 12. Examples of pressing marks

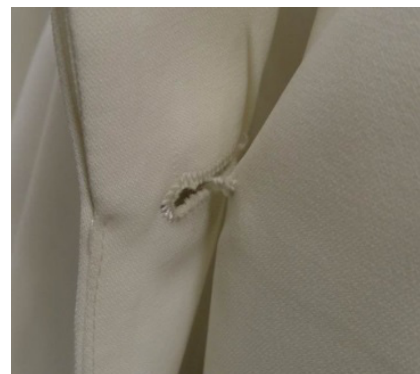

(a) C4

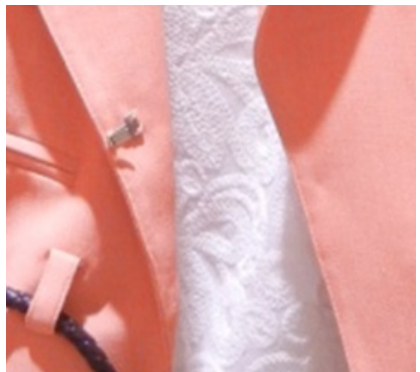

(b) $\mathrm{C5}$

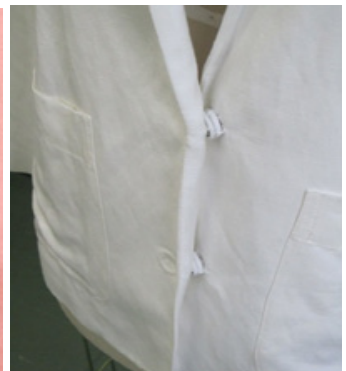

(c) $\mathrm{C} 12$

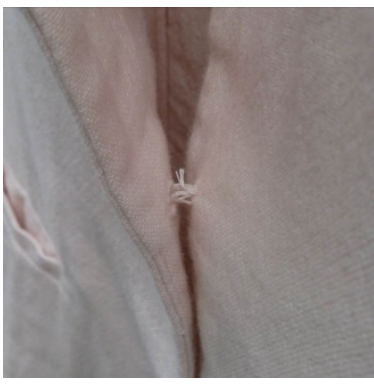

(d) $\mathrm{C} 13$

Figure 13. Examples of buttons that are easy to unbutton

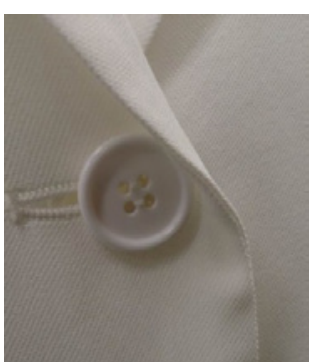

(a) $\mathrm{C8}$

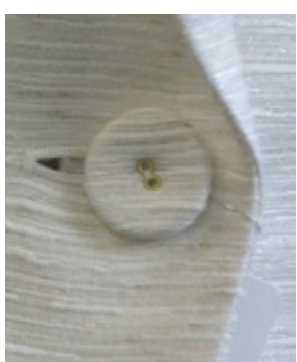

(b) J9

Figure 14. Poor-quality button (a) and high-quality button (b) 
makers when entering the Japanese and Chinese markets, we asked apparel experts in Japan and China to evaluate jackets and dresses that were purchased in Chinese and Japanese department stores. We also investigated the marketability of Chinese apparel in Japanese department stores.

Results showed that Japanese experts considered general design and sewing finish in a comprehensive manner when evaluating clothing. The Chinese experts, on the other hand, put more emphasis on design points, while tending to evaluate materials and sewing finish independently. Taken as a whole, our results reveal that clothing evaluating viewpoints vary between Japan and China, despite there being some common points of evaluation. These results are also related to the differences of customers' preference of each country.

For the marketability of Chinese clothing in Japanese department stores by Japanese evaluators, half of the Chinese clothing samples were judged as unsaleable, primarily because the sewing quality was incompatible with Japanese standards, the designs were judged as outdated, and the materials were of low quality. However, the other half of the Chinese clothing samples received high evaluations of marketability in Japan because of their designs and sewing quality. To obtain generally higher evaluations, Chinese clothing needs to be improved in the aspects of sewing finish, quality of materials, and design to be saleable in the Japanese apparel market. Outdated design in Japan was considered as not old in China. Chinese customer accepted relatively low level of sewing and material quality. These differences of the preference may exist because of the customers' experience and the influence of their culture on fashion.

In this study, we assumed that the experts understand the customers' preferences and marketability of each country. If the assumption is proper, their evaluation represents the customers' one. Thus, we considered their evaluation as that of the customers. Therefore, our results clarified that it is necessary to take into account the evaluation points considered to be more important in each country when making efforts to increase the globalisation of apparel products. This result will help designers and manufacturers to make clothing, which satisfy customers in each country.

\section{ACKNOWLEDGEMENT}

This work was supported by JSPS KAKENHI Grant number 24220012 and 23240100.

\section{References}

1. Ministry of Economy, Trade and Industry of Japan. (2013). Recent trends in the textile and fashion industry. Retrieved July 3, 2013, http://www.meti.go.jp/committee/ summary/0004638/004_03

2. Ministry of Economy, Trade and Industry of Japan.(2013) Recent trends in the textile and fashion industry. Retrieved July 3, 2013, http://www.meti.go.jp/committee/materials2/ downloadfiles/g9 1225f07j.pdf

3. Masuda T. (2010). Over-quality problem concealed in the Japanese market, The Nihon Keizai Shimbun evening paper „JUJIRO.

4. Sakaguchi M.(2006). The second period agenda to enter the Chinese market for the Japanese-apparel, Sen'i Torendo, November/December issue 2006, pp. 30-33.

5. O'Cass A.\& Siahtiri V. (2013). In search of status through brands from Western and Asian origins: Examining the changing face of fashion clothing consumption in Chinese young adults Original Research Article, Journal of Retailing and Consumer Services, 20(6), 505-515.

6. Zhang B. \& Kim J. (2013). Luxury fashion consumption in China: Factors affecting attitude and purchase intent Original Research Article, Journal of Retailing and Consumer Services, 20(1), 68-79.

7. Tai S. H.C.(2005). Shopping styles of working Chinese females, Journal of Retailing and Consumer Services, 12(3), 191-203.

8. Laforet S. \& Chen J. (2012). Chinese and British consumers' evaluation of Chinese and international brands and factors affecting their choice, Journal of World Business, 47(1), 54-63.

9. Mellor D., Waterhouse M., Mamat N. H. b., Xu X., Cochrane J., McCabe M., \& Ricciardelli L.(2013). Which body features are associated with female adolescents' body dissatisfaction? A cross-cultural study in Australia, China and Malaysia, Body Image, 10(1), 54-61.

10. Luo Y., Parish WL \& Laumann E. (2005). A populationbased study of body image concerns among urban Chinese adults, Body Image, 2(4) 333-45.

11. Clothes industry network in China. (2013). Retrieved July 15, 2013, http://www.efuin.com/News/news_detail. aspx? ID=90983.

12. Yano research institute Ltd.,(2012). Analysis of the strategy of major companies and the actual situation of China fashion industry 2012, http://www.yano.co.jp/market_ reports/C53205600. 